SFB

Default risk premia on government bonds in a quantitative macroeconomic model

823

Falko Juessen, Ludger Linnemann,

Andreas Schabert

Nr. 33/2009

$\mathcal{O}$

$\longrightarrow$

ర్

ט)

(1)

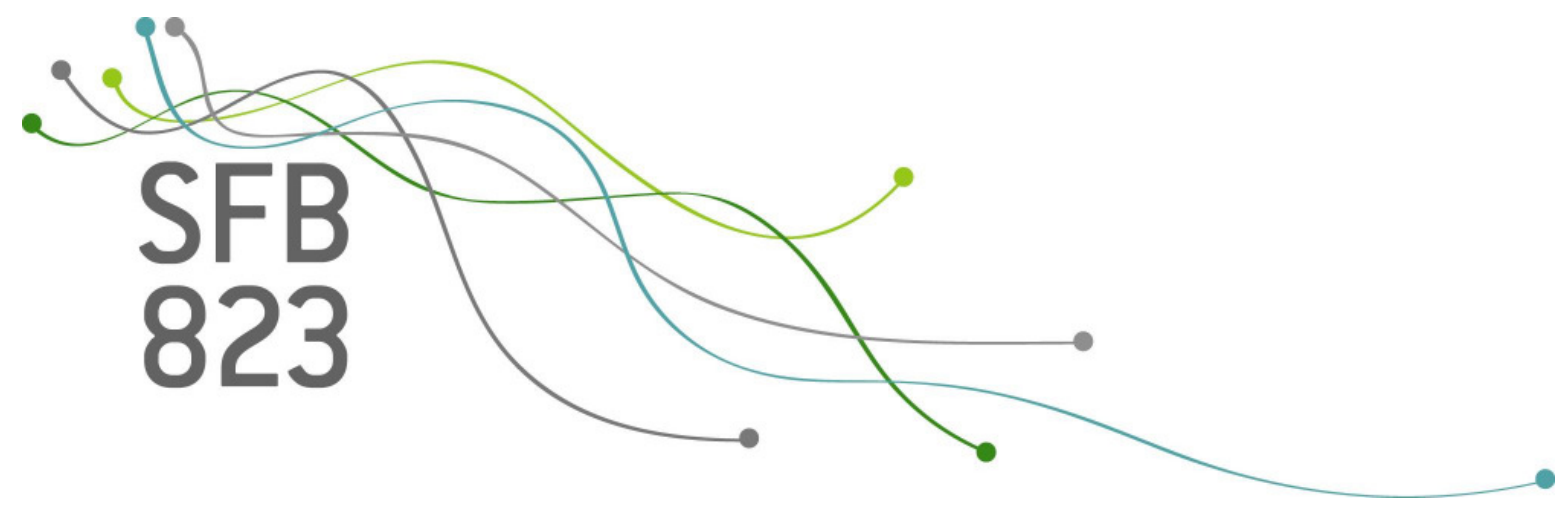





\title{
Default risk premia on government bonds in a quantitative macroeconomic model
}

\author{
Falko Juessen \\ TU Dortmund University \\ Ludger Linnemann ${ }^{1}$ \\ TU Dortmund University \\ Andreas Schabert \\ TU Dortmund University and University of Amsterdam
}

This version: November 16, 2009

\begin{abstract}
This paper examines the pricing of public debt in a quantitative macroeconomic model with government default risk. Default may occur due to a fiscal policy that does not preclude a Ponzi game. When a build-up of public debt makes this outcome inevitable, households stop lending such that the government has to default. Interest rates on government bonds reflect expectations of this event. There may exist multiple bond prices compatible with a rational expectations equilibrium. We analyze the conditions under which expected default risk premia can quantitatively rationalize sizeable spreads on public bonds. Sovereign default risk premia turn out to emerge at either very high debt to output ratios, or if the variance of productivity shocks is large.
\end{abstract}

Keywords: Sovereign default, asset pricing, fiscal policy, government debt JEL: E62, G12, H6, E32

\footnotetext{
${ }^{1}$ Corresponding author. Address: TU Dortmund University, Department of Economics, Vogelpothsweg 87, D-44227 Dortmund, Germany. Email: ludger.linnemann@tu-dortmund.de. Financial support from the German Science Foundation (DFG), SFB 823, is gratefully acknowledged.
} 


\section{Introduction}

Recent fiscal policy measures that aim to reduce the macroeconomic impact of the financial crisis have boosted public deficits in almost all industrialized countries. According to the International Monetary Fund (IMF, 2009) gross public debt in the G20 countries will surge to $106 \%$ of GDP by 2010 . As a consequence, concerns about future government default on debt obligations have become a topic widely discussed in the financial press, as well as the possibility of interest rates on government bonds rising as a reflection of default risk. Indeed, sizeable yield spreads between government bonds of member countries of the European Monetary Union have been observed over the course of recent years, even before the current crisis.

For example, in mid 2007 the interest rates on one year government obligations in the highly indebted countries Belgium and Greece (who had debt to gdp ratios of 88.7 and 96.5 percent) were 23.7 and 113.9 basis points, respectively, above the interest rates on comparable German government bonds. ${ }^{2}$ For longer term government securities of Eurozone members, there is a well documented empirical pattern showing that interest rate spreads exist and are increasing in the level of a country's indebtedness (see e.g. Manganelli and Wolswijk, 2009). Since, within a currency union, government bonds of all member countries are subject to the same amount of inflation risk and there is no differential exchange rate risk, this divergence in interest rates could be interpreted as reflecting the risk of governments defaulting on their debt obligations. One obvious policy concern would be that higher interest rates on sovereign debt instruments due to default risk premia additionally worsen the fiscal position of indebted governments.

The present paper analyzes government default risk and its reflection in public bond interest rates within a quantitative macroeconomic model, where default is modelled similar to Uribe's (2006) "Fiscal Theory of Sovereign Default". The question is whether sizeable risk premia on short-term debt amounting from several tens to over a hundred basis points can be rationalized when interest rates are equilibrium outcomes reflecting the principles of consumption based asset pricing. While the empirical literature has documented the existence of spreads that may be interpreted as risk premia (see e.g. Codogno et al., 2003, Bernoth et al., 2006, Akitobi and Stratmann, 2008), it is presently unclear in how far the emergence of sovereign default risk premia for countries without recent default experiences can be explained within a dynamic general equilibrium framework that is the standard workhorse of contemporary macroeconomics. The present paper addresses this question.

There is, of course, a large theoretical literature on sovereign default that focuses on

\footnotetext{
${ }^{2}$ Data refer to yields of newly issued one year central government securities and were collected from the countries' respective Treasury internet sites; data on debt to gdp ratios is from Eurostat.
} 
external debt in open economies. In this literature, default is modelled as a deliberate strategic decision of the government that reflects the outcome of an optimization problem (see Eaton and Gersovitz, 1981, or Arellano, 2008, among others). While this assumption is certainly useful for the case where it has been applied to in the literature, namely external debt of emerging market economies, we view it as less suited to explain risk premia in developed economies where governments have not been observed defaulting on their debt in the recent past. Since sovereign default has not occurred in, for example, member countries of the European Union in the postwar period, yet public bonds issued by these countries' governments are priced differently from each other, we decide not to model default as a purposefully chosen action of the government. ${ }^{3}$ Instead, our approach is complementary to the existing literature in that we analyze default risk based on a nonoptimizing government issuing short-term debt while facing a maximum debt repayment capacity. In our framework, the government honors its debt obligations as far as possible, but default inevitably occurs if lenders stop rolling over public debt, which will be the case when the government becomes unable to avoid a Ponzi game (even for the maximum present value of future government surpluses). As a consequence, while government default may occur in equilibrium, it is a rare event in our model. We use this setup to infer the pricing of default risk.

Specifically, we study a stylized closed economy that is subject to serially correlated shocks to labor productivity. The government levies a proportional tax on labor income (there are no lump-sum taxes available) and issues non-state contingent one-period debt contracts in order to finance a given stream of real government expenditures. According to these contracts, the government repays debt with a predetermined real interest rate. In case of default, lenders can just seize current net revenues from the government, a situation that differs from private credit relations where the lender may become a claimant on future profit streams. The only risk associated with bond investments is default risk, since we assume that bonds are real so that debt revaluations via price level shifts (which are the focus in the fiscal theory of the price level, see Woodford, 1994, Sims, 1994, or Niepelt, 2004) are impossible.

This is one aspect that distinguishes our approach to sovereign default from the otherwise closely related work by Uribe (2006), who considers nominal debt and exogenous surpluses in an endowment economy to demonstrate that default is inevitable under certain monetary-fiscal policy regimes. Most relevant to our context is Uribe's (2006) scenario

\footnotetext{
${ }^{3}$ Our approach can further be motivated by the empiricial evidence in Reinhart and Rogoff (2008), who find that in surprisingly many cases default does not involve external debt. Therefore, the open economy focus of the previous literature may not capture important aspects, a gap that we attempt to fill by our model of internal government default.
} 
under price level targeting, where he determines default rates by applying simple fiscal closing rules (e.g. to default if the current tax-to-debt ratio exceeds some positive constant). In this paper, we instead introduce the assumption that investors stop lending in the case where a government Ponzi-game becomes inevitable, which allows us to determine an entire sequence of default rates. ${ }^{4}$ By considering productivity shocks, which give rise to endogenous primary surpluses and stochastic discount factors, we quantitatively assess the determination and the magnitude of default risk premia using consumption based bond prices.

The central assumption is that the government sets taxes in a way that does not rule out Ponzi schemes. If adverse productivity shocks make the present value of future surpluses fall short of covering the level of outstanding debt even with the revenue maximizing tax rate - which is well defined here, because with only labor income taxation there is a tax Laffer curve with an interior maximum -, applied for the entire future, the government's maximum debt repayment capacity is exceeded. A potential household-lender who realizes that he would support a Ponzi game if he invested in government bonds will stop lending to the government. In this case, default becomes inevitable and current surpluses are distributed to bond holders, who therefore experience only a partial redemption of their investments. Each individual lender will assess the probability that this event will occur in the next period and will consequently demand a default risk premium as a compensation for expected losses.

We use the model to assess the influence of the level of government debt in relation to output and of changes in labor productivity on risk premia. The main results are as follows.

First, there are either no or multiple equilibrium prices for government debt. In particular, two interest rates on government bonds can exist in equilibrium: both a combination of high interest rates, high default risk, and high public debt, as well as one of low interest rates, low default risk, and low public debt can be compatible with the expected rate of return of investors and with the government's demand for external funds. Default immediately occurs if the lenders coordinate their expectations on a high risk equilibrium, thereby imposing an unsustainable financing burden on the government through high risk premia.

Second, when we focus on the low equilibrium interest rate, which exhibits plausible comparative static properties, default premia can occur for a wide range of productivity levels and monotonically increase with the initial debt level. We find substantial risk

\footnotetext{
${ }^{4}$ Without such an assumption or Uribe's (2006) fiscal closing rules, default rates (and rational expectations thereof) can only be determined in the initial period, as shown in Schabert's (2009) analysis on monetary policy and equilibrium determinacy.
} 
premia (even at low to moderate debt levels) when innovations to the productivity process are assumed to be uniformly distributed.

Third, we apply a calibrated version of the model with normally distributed innovations to a serially correlated productivity level. Interestingly, we find that risk premia may emerge over time even if the initial stock of public debt does not exceed the present value of expected future surpluses. However, for the model to be able to explain pervasive risk premia, the productivity process has to be characterized either by low levels of serial correlation or by high innovation variances, such that an extremely unfavorable state has a non-negligible probability. In order to rationalize the empirically observed coexistence of moderately high debt to gdp ratios and sizeable interest rate spreads interpreted as risk premia, the implied variance of output would have to be much higher than has been the case in historical data. For productivity processes that are typically used in business cycle research, we find that default risk premia occur only rarely, and only at very high ratios of debt over output.

The remainder is organized as follows. Section 2 introduces the model and shows how we derive expected default risk and the ensuing premium on public bonds. Section 3 describes the determination of equilibrium risk premia. Section 4 presents results for two versions of the model differing in the assumptions about the distribution of productivity shocks. Section 5 concludes.

\section{The model}

In this section we present a simple real dynamic general equilibrium model where the government levies income taxes and issues non-state contingent one period debt. We consider the case where fiscal policy does not guarantee that the government never runs a Ponzi-game. ${ }^{5}$ Households are assumed to stop lending to the government when they realize that a Ponzi scheme is inevitable. Without further access to credit, the government defaults while lenders can seize current net revenues. Households know that this event is possible when adverse productivity shocks lead to a build-up of public debt. They form expectations of the future fractional rate of repayment of government debt. Accordingly, equilibrium in the asset market requires that risk premia exist in order to compensate household-lenders for the risk of government default.

\subsection{The private sector}

There exists a continuum of infinitely lived and identical households of mass one. Their utility increases in consumption $c_{t}$ and decreases in working time $l_{t}$, the latter variable

\footnotetext{
${ }^{5}$ This assumption is analoguous to the fiscal policy specification in Uribe (2006) and in the fiscal theory of the price level (see Sims, 1994, and Woodford, 1994). In contrast to these studies, in our purely real model the price level is irrelevant.
} 
being bounded by a unit time endowment such that $l_{t} \in(0,1)$. The objective of a representative household is given by

$$
\max E_{s} \sum_{t=0}^{\infty} \beta^{t}\left[\ln c_{t+s}+\frac{1-l_{t+s}}{\gamma}\right], \quad \text { with } \beta \in(0,1), \gamma>0
$$

where $\beta$ denotes the discount factor. Households borrow and lend among each other via one-period private debt contracts. Private debt is introduced here to define a risk free interest rate $R_{t}^{r f}$. Let $d_{t-1}$ denote the beginning of period net private asset position and $1 / R_{t}^{r f}$ the period-t-price for a payoff of one unit of output in period $t+1$. We restrict our attention to the case where private debt contracts are enforceable and households satisfy the borrowing constraint

$$
\lim _{t \rightarrow \infty}\left(d_{t+s} / R_{t+s}^{r f}\right) \prod_{i=1}^{t} 1 / R_{s+i-1}^{r f} \geq 0 .
$$

Utility maximization subject to the borrowing constraint (2) requires the following first order condition for borrowing and lending in terms of private debt (i.e. the consumption Euler equation) to be satisfied

$$
c_{t}^{-1}=R_{t}^{r f} \beta E_{t}\left(c_{t+1}^{-1}\right),
$$

as well as the transversality condition

$$
\lim _{t \rightarrow \infty} E_{s}\left(d_{t+s} / R_{t+s}^{r f}\right) \prod_{i=1}^{t} 1 / R_{s+i-1}^{r f}=0 .
$$

Households can further invest in one-period government bonds $b_{t}$, subject to $b_{-1}>0$ and $b_{t} \geq 0$. The government offers one-period debt contracts at the price $1 / R_{t}$ in period $t$ that promise to deliver one unit of output in period $t+1$. In contrast to private borrowers, the government does not guarantee full debt repayment. In case of default the lenders will proportionally be served with current net revenues. It should be noted that this differs from the case of lending to a firm, where default typically leads to lenders' taking over the firm as a claimant on future profit streams through a debt-to-equity swap. In the present context, however, households cannot become shareholders of the government, such that lenders cannot seize more than current net revenues.

If current and discounted future surpluses are expected to be large enough to repay outstanding debt, the household optimality condition for investment in government bonds would be the analogue to the Euler equation (3), namely, $c_{t}^{-1}=R_{t} \beta E_{t}\left(c_{t+1}^{-1}\right)$. The requirement $b_{t} \geq 0$ further requires that in the household optimum the transversality 
condition

$$
\lim _{t \rightarrow \infty} E_{s}\left(b_{t+s} / R_{t+s}\right) \prod_{i=1}^{t} 1 / R_{s+i-1}^{r f}=0
$$

holds, where $R_{t+s}=R_{t+s}^{r f}$ when the government fully services its debt obligations. If beginning-of-period public debt exceeds a level that is too high to be repayable even for the maximum present value of budget surpluses (see section 2.2 for a precise definition of these), the government runs into a Ponzi game, which would be inconsistent with the households' transversality condition (5). In this case, households are assumed to stop lending to the government, which necessarily implies that the government defaults in period $t$, i.e. can honor only a fraction of its debt obligations out of current surpluses.

Since households are assumed to have rational expectations, they realize the possibility of partial default on government bonds and account for the probability of default (of course, since households are atomistic, an individual investor does not take into consideration the influence of his behavior on the probability of default). Let $1-\delta_{t}$ denote the fraction of government bonds that is redeemed and $\delta_{t} \in[0,1]$ the default rate. The household flow budget constraint then reads

$$
c_{t}+\left(b_{t} / R_{t}\right)+\left(d_{t} / R_{t}^{r f}\right) \leq\left(1-\tau_{t}\right) w_{t} l_{t}+\left(1-\delta_{t}\right) b_{t-1}+d_{t-1}+\pi_{t}
$$

where $\pi_{t}$ are firms' profits, and labor income $w_{t} l_{t}$ (with the real wage rate $w_{t}$ ) is subject to a proportional tax rate $\tau_{t} \in(0,1)$. The household optimum is characterized by the first order conditions (3),

$$
\begin{aligned}
c_{t} & =\gamma\left(1-\tau_{t}\right) w_{t}, \\
c_{t}^{-1} & =R_{t} \beta E_{t}\left(c_{t+1}^{-1}\left(1-\delta_{t+1}\right)\right),
\end{aligned}
$$

and the transversality conditions (4) and (5). Note that the Euler equation for risky government debt, (7), differs from the one for risk-free private debt (3), in that the pricing of government bonds is affected by the fact that repayment is expected to be only partial because of possible future default.

If debt $b_{t+s-1}$ at the beginning of some period $t+s$ is too large such that a Ponzi game becomes inevitable, households do not lend to the government, i.e. the end of period debt equals zero, $b_{t+s}=0$, and the government defaults. Lending may resume, however, in the subsequent periods, when partial default has ameliorated the fiscal position.

Perfectly competitive firms produce the output good $y_{t}$ with a simple linear technology

$$
y_{t}=a_{t} l_{t}
$$


where labor productivity $a_{t}$ is generated by

$$
a_{t}=\rho a_{t-1}+(1-\rho) \bar{a}+\varepsilon_{t}
$$

here $\bar{a}>0$ is a constant long-run average productivity level, the persistence parameter is $\rho \in(0,1)$, and $\varepsilon_{t}$ is an i.i.d. zero mean random variable. For the analysis of risk premia, we will consider two different distributions for the innovations $\varepsilon_{t}$ below in sections 4.1 and 4.2. Labor demand satisfies

$$
w_{t}=a_{t}
$$

\subsection{The public sector}

The government does not have access to lump-sum taxation. It raises revenues by issuing debt and taxing labor income, and purchases an exogenously given amount $g_{t}$ of the final good in each period. Throughout, we assume government spending to be constant, $g_{t}=g>0$. The underlying assumption is that political constraints make a certain amount of government spending inevitable. The flow budget constraint is given by

$$
b_{t} R_{t}^{-1}+s_{t}=\left(1-\delta_{t}\right) b_{t-1}
$$

where the surpluses $s_{t}$ equal tax revenues net of expenditures,

$$
s_{t}=\tau_{t} w_{t} l_{t}-g
$$

The government does not guarantee to fully service debt. We assume that the government does not preclude that public debt might evolve on a path that implies a Ponzi scheme. Since households are not willing to engage in such schemes, they may stop lending and (temporarily) disrupt the government from access to credit.

To see this, consider, for a moment, the default free case, i.e. presume the nonrepayment rate $\delta_{t+k}$ were equal to zero for all $k \geq 0$. In this case, one would obtain by iterating the government flow budget constraint (11) forward and taking expectations, $\delta_{t+k}=0 \quad \forall k \geq 0 \Rightarrow$

$$
b_{t-1}=E_{t} \sum_{k=0}^{\infty} s_{t+k} \prod_{i=1}^{k}\left(1 / R_{t+i-1}\right)+\lim _{k \rightarrow \infty} E_{t} b_{t+k} R_{t+k}^{-1} \prod_{i=1}^{k} \frac{1}{R_{t+i-1}} .
$$

Now suppose that outstanding debt $b_{t-1}$ exceeds the present value of future surpluses, i.e. the first term on the right hand side of (13). Then, the limit term would exceed zero, $\lim _{k \rightarrow \infty} E_{t} b_{t+k} R_{t+k}^{-1} \prod_{i=1}^{k} 1 / R_{t+i-1}>0$. By definition, the government would then run into a Ponzi game. But this, together with $R_{t+k}=R_{t+k}^{r f} \forall k \geq 0$ for $\delta_{t}=0$ (see 3 and 7) would be inconsistent with the households' transversality condition (5). As mentioned 
above, we assume that households will then stop lending to the government, such that $b_{t}=0$ in that period. The only way for the government budget constraint (11) to be satisfied in this case is through default in the sense $\delta_{t}>0$.

As a specific way to implement a fiscal policy that entails default risk in this sense, we assume that the government keeps the tax rate constant, $\tau_{t}=\tau$. This is a prominent example of a large class of fiscal rules that do not incorporate enough self-corrective behavior on the part of the government as to avoid Ponzi schemes in each period of time. ${ }^{6}$ However, it can also be viewed as a natural benchmark in this framework: if government bonds were state contingent, it is well-established that in this type of model an optimal income tax rate under commitment (and without default) would have to be constant and sufficiently large to finance initial outstanding debt and future expenditures (see e.g. Ljungqvist and Sargent, 2004). In this paper, government bonds are however non-state contingent, which implies that this type of tax policy is in general not consistent with a set of 'measurability constraints' for each period that relate the present value of future surpluses to the beginning of period stock of public debt to rule out Ponzi games (see Ayiagari et al., 2002). The choice of a constant tax rate can thus, besides being a simple example, be seen as the behavior of a government that ignores this subtle difference and sets the tax rate as if debt were state contingent.

Note that there exists a maximum value for the present value of future surpluses, which we call the maximum debt repayment capacity. The latter is the maximum amount of debt that the government would be able to repay if it imposes the revenue maximizing tax rate for the entire future. A well defined revenue maximizing tax rate, $\tau^{*}$, exists because with proportional labor income taxation there is a tax Laffer curve with an interior maximum (see section 2.3 for an explicit derivation). We denote the period $t$ value of the maximum debt repayment capacity by $\Psi_{t}$, defined as

$$
\Psi_{t}=E_{t} \sum_{k=0}^{\infty} s_{t+k}^{*} \prod_{i=1}^{k} 1 / R_{t+i-1}^{r f} .
$$

Here, $s_{t+k}^{*}=\tau^{*} w_{t+k}^{*} l_{t+k}^{*}-g$ is the maximum period surplus that is obtained if the revenue maximizing tax rate $\tau^{*}$ is applied. This leads to corresponding levels of labor income denoted $w_{t+k}^{*} l_{t+k}^{*}$ and the risk free rate $R_{t+k}^{r f}$ is applied for discounting. ${ }^{7}$ Note that house-

\footnotetext{
${ }^{6}$ This assumption rules out the debt stabilizing behavior that has been found by Bohn (1998) to characterize US fiscal policy empirically.

${ }^{7}$ Note that the maximum debt repayment capacity bears a resemblance to Aiyagari's (1994) natural debt limit for consumers. Private households cannot accumulate more debt than would be expected to be repaid by pledging the entire stream of future incomes. While households are assumed to respect the natural private debt limit (as a borrowing constraint), the government is not constrained in an analogous way, which is why default may occasionally occur in our model.
} 
holds will account for the maximum debt repayment capacity for their lending decision in equilibrium. We thereby allow for the case where the current tax rate differs from revenue maximizing tax rate, which could in principle be implemented by future governments.

The maximum initial debt level that can be expected to be repaid without default is thus characterized by $b_{t-1}=\Psi_{t}$. The government will fully serve debt obligations if $b_{t-1} \leq \Psi_{t}$. As long as this is the case, no government default occurs. Default, however, becomes inevitable if the current stock of debt exceeds the maximum repayment capacity:

$$
b_{t-1}>\Psi_{t}
$$

If this is the case, no constant tax rate is able to generate enough current and future revenues to enable full repayment of outstanding debt.

In the case where (15) is satisfied, (13) with $R_{t+k}=R_{t+k}^{r f} \forall k \geq 0$ is inconsistent with the transversality condition (5) and no individual household is willing to lend to the government. The consequence is that aggregate lending to the government comes to a halt, such that end-of-period debt equals zero, $b_{t}=0$, in the current period. The government is then unable to fully honor its obligations and redeems as much as possible of its outstanding debt out of current surpluses. As a consequence, repayment will only be partial. The non-repayment rate $\delta_{t}$ in the case (15) satisfies $\delta_{t}=1-s_{t} / b_{t-1}$ (see 11).

To sum up, if beginning-of-period debt $b_{t-1}$ is smaller than $\Psi_{t}$, households are willing to lend to the government according to (7), while the government does not default in period $t, \delta_{t}=0$, and borrows to balance its budget such that end-of-period debt equals $b_{t}=\left(b_{t-1}-s_{t}\right) R_{t}$. The price of debt, $1 / R_{t}$, then reflects the probability of default in $t+1$. If, however, beginning-of-period debt is too high such that (15) is satisfied, households stop lending. The government then has to default and repays debt as far as possible, with a default rate equal to $\delta_{t}=1-s_{t} / b_{t-1}$. In the period subsequent to a default event, the stock of government debt is zero and default is not possible in the next period, such that households are again willing to lend to the government (of course taking the endogenous probability of further future defaults into account).

\section{Equilibrium}

In equilibrium, prices adjust to clear markets for goods, labor, and assets and the net stock of risk-free private debt $d_{t}$ is zero in the aggregate. Households' initial asset endowments are assumed to be positive, i.e. the government is initially indebted. A rational expectations equilibrium is a set of sequences $\left\{c_{t}, l_{t} \in[0,1], y_{t}, w_{t}, b_{t} \geq 0, \delta_{t} \in[0,1], R_{t}^{r f}\right.$, 
$\left.R_{t}, s_{t}\right\}_{t=0}^{\infty}$ satisfying (3), (6), (7), (8), (10), (12) and

$$
\begin{aligned}
& y_{t}=c_{t}+g_{t} \text {, } \\
& b_{t}=\left\{\begin{array}{ccc}
\left(b_{t-1}-s_{t}\right) R_{t} & \text { if } \Psi_{t} \geq b_{t-1} \\
0 & \text { if } \Psi_{t}<b_{t-1}
\end{array},\right. \\
& \delta_{t}=\left\{\begin{array}{cl}
0 & \text { if } \quad \Psi_{t} \geq b_{t-1} \\
1-s_{t} / b_{t-1} & \text { if } \quad \Psi_{t}<b_{t-1}
\end{array},\right.
\end{aligned}
$$

(4), (5), and (14), a fiscal policy setting $\tau \in[0,1]$, given $\left\{a_{t}\right\}_{t=0}^{\infty}, g>0$, and initial debt $b_{-1}>0$.

The equilibrium allocation is not directly affected by public debt and the (expected) default rate. The first property is due to the fact that the labor income tax is assumed not to be contingent on the fiscal stance. The second property follows from the fact that default does not lead to any kind of resource losses or distortions. Of course, the price of government bonds will depend on the expected default rate, which can be seen from the asset pricing equation (7). This reflection of the probability of future default in the interest rate on government bonds is our main object of study.

The equilibrium sequences of consumption, working time, output, the wage rate, the risk free rate and government surpluses $\left\{c_{t}, l_{t}, y_{t}, w_{t}, R_{t}^{r f}, s_{t}\right\}_{t=0}^{\infty}$ are determined for given $g$ and $\left\{a_{t}\right\}_{t=0}^{\infty}$ by (6), (8), (10), (12) and (16), which can be summarized by

$$
\begin{aligned}
c_{t} & =c\left(a_{t}, \tau\right):=\gamma(1-\tau) a_{t} \\
l_{t} & =l\left(a_{t}, \tau\right):=\left(c\left(a_{t}, \tau\right)+g\right) / a_{t} \\
s_{t} & =s\left(a_{t}, \tau\right):=\tau c\left(a_{t}, \tau\right)-(1-\tau) g \\
R_{t}^{r f} & =c\left(a_{t}, \tau\right)^{-1} \beta^{-1} / E_{t}\left(c\left(a_{t+1}, \tau\right)^{-1}\right)
\end{aligned}
$$

as well as $w_{t}=a_{t}$ and $y_{t}=a_{t} l\left(a_{t}, \tau\right) .^{8}$

While the equilibrium sequences $\left\{c_{t}, l_{t}, y_{t}, w_{t}, s_{t}\right\}_{t=0}^{\infty}$ are not affected by sovereign default, these variables are of course correlated with the default rate $\delta_{t}$ due to changes in the state $a_{t}$. In any case, they will be stationary, given that the state $a_{t}$ is stationary.

With the above solutions, we can easily identify a time-invariant tax rate to compute the maximum debt repayment capacity (14). We look for a feasible tax rate $\tau^{*} \in(0,1)$ that maximizes tax revenues for the case where the state equals its mean $\left(a_{t}=\bar{a}\right), \tau w l=$ $\tau[\gamma(1-\tau) \bar{a}+g]$. This tax rate satisfies $F\left(\tau^{*}\right):=g+\bar{a} \gamma\left(1-2 \tau^{*}\right)=0$, such that the

\footnotetext{
${ }^{8}$ If default occurs $\left(\delta_{t}=1-s_{t} / b_{t-1}\right)$ the budget constraints imply $c_{t}=\left(1-\tau_{t}\right) w_{t} l_{t}+\left(1-\delta_{t}\right) b_{t-1}=$ $\left(1-\tau_{t}\right) w_{t} l_{t}+s_{t}$ and thus $y_{t}=a_{t} l_{t}=c_{t}+g$.
} 
unique tax rate $\tau^{*}$ that maximizes tax revenues is given by

$$
\tau^{*}=\frac{1}{2}+\frac{g}{2 \bar{a} \gamma} .
$$

In order to determine the default rate and its expected value, we need to check in every period if the level of debt exceeds the maximum debt repayment capacity and to compute expectations about future defaults. As can be seen from (34), the maximum debt repayment capacity is solely a function of (policy and preference) parameters and of the current and future exogenous states of the economy. Given that it contains expectations of a non-linear function of future states, we apply a second order approximation of $\Psi_{t}$. Though public debt might not be stationary, we can exploit the fact that the exogenous state variable $a_{t}$ is stationary and apply a local approximation of $\Psi_{t}$ at the unconditional mean $\bar{a}$. In appendix 7.1, we show that $\Psi_{t}$ can be approximated by:

$$
\begin{aligned}
& \Psi\left(a_{t}, \sigma_{\varepsilon}, \rho, \tau^{*}\right) \simeq \gamma\left(1-\tau^{*}\right) a_{t} \cdot\left\{\frac{f(\bar{a})}{1-\beta}+\frac{f^{\prime}(\bar{a})}{1-\beta \rho}\left(a_{t}-\bar{a}\right)\right. \\
& \left.+\frac{\frac{1}{2} f^{\prime \prime}(\bar{a})}{1-\rho^{2}}\left(\left(\frac{\sigma_{\varepsilon}^{2}}{1-\beta}-\frac{\sigma_{\varepsilon}^{2}}{1-\beta \rho^{2}}\right)+\frac{\left(1-\rho^{2}\right)\left(a_{t}-\bar{a}\right)^{2}}{1-\beta \rho^{2}}\right)\right\} .
\end{aligned}
$$

According to $(23), \Psi_{t}$ is a function only of today's state and time invariant parameter values. Due to this property we can easily compute equilibrium values for the expected default rate, public debt, and the bond price in a recursive way.

The expected default rate, public debt, and the bond price have to be determined simultaneously using the equilibrium conditions (7), (17), and (18). In order to identify these solutions, we have to consider the probabilities of the two distinct cases $\Psi_{t} \geq b_{t-1}$ and $\Psi_{t}<b_{t-1}$.

Let $a_{t}^{*}$ be the productivity level that leads to a maximum debt repayment capacity $\Psi_{t}$ that exactly equals $b_{t-1}$,

$$
a_{t}^{*}: \Psi\left(a_{t}^{*}, \sigma_{\varepsilon}, \rho, \tau^{*}\right)=b_{t-1} .
$$

Thus, $a_{t}^{*}$ is the minimum productivity level that allows full debt repayment and thus precludes default; we will refer to this as the productivity threshold. Further, let $\pi_{t}\left(a_{t+1}\right)=$ $\pi\left(a_{t+1} \mid a_{t}\right)$ be the probability of a particular value $a_{t+1}$ conditional on $a_{t}$. Then, the probabilities of default and of non-default in $t+1$ conditional on the information in $t$ are

$$
\begin{aligned}
& \operatorname{prob}\left(\Psi_{t+1}<b_{t} \mid a_{t}, b_{t}\right)=\int_{-\infty}^{a_{t+1}^{*}} \pi_{t}\left(a_{t+1}\right) d a_{t+1}, \\
& \operatorname{prob}\left(\Psi_{t+1} \geq b_{t} \mid a_{t}, b_{t}\right)=\int_{a_{t+1}^{*}}^{\infty} \pi_{t}\left(a_{t+1}\right) d a_{t+1} .
\end{aligned}
$$

We now rewrite the asset pricing equation (7), which includes the expectation term 
$E_{t}\left[c_{t+1}^{-1}\left(1-\delta_{t+1}\right)\right]$. We thereby have to account for the possibility that consumption and the default rate are not independent. According to the assumptions in section 2.2, the default rate $\delta_{t+1}$ equals zero if $\Psi_{t+1} \geq b_{t}$, and $\delta_{t+1}=1-s_{t+1} / b_{t}$ if $\Psi_{t+1}<b_{t}$. Hence, $E_{t}\left[c_{t+1}^{-1}\left(1-\delta_{t+1}\right)\right]$ is given by

$$
\begin{aligned}
& E_{t}\left[c_{t+1}^{-1}\left(1-\delta_{t+1}\right)\right] \\
= & \int_{-\infty}^{a_{t+1}^{*}} \pi_{t}\left(a_{t+1}\right)\left[c_{t+1}^{-1} \cdot\left(s_{t+1} / b_{t}\right)\right] d a_{t+1}+\int_{a_{t+1}^{*}}^{\infty} \pi_{t}\left(a_{t+1}\right)\left[c_{t+1}^{-1} \cdot(1-0)\right] d a_{t+1} \\
= & b_{t}^{-1} \int_{-\infty}^{a_{t+1}^{*}} \pi_{t}\left(a_{t+1}\right)\left[c\left(a_{t+1}, \tau\right)^{-1} s\left(a_{t+1}, \tau\right)\right] d a_{t+1}+\int_{a_{t+1}^{*}}^{\infty} \pi_{t}\left(a_{t+1}\right)\left[c\left(a_{t+1}, \tau\right)^{-1}\right] d a_{t+1},
\end{aligned}
$$

where we used the solutions (19) and (21). The asset pricing equation (7) can thus be written as

$$
\begin{aligned}
& 1 / R_{t}=\beta \frac{E_{t}\left[c_{t+1}^{-1}\left(1-\delta_{t+1}\right)\right]}{c_{t}^{-1}} \Rightarrow 1 / R_{t}= \\
& \frac{\beta}{c_{t}^{-1}}\left[b_{t}^{-1} \int_{-\infty}^{a_{t+1}^{*}} \pi_{t}\left(a_{t+1}\right)\left[c\left(a_{t+1}, \tau\right)^{-1} s\left(a_{t+1}, \tau\right)\right] d a_{t+1}+\int_{a_{t+1}^{*}}^{\infty} \pi_{t}\left(a_{t+1}\right)\left[c\left(a_{t+1}, \tau\right)^{-1}\right] d a_{t+1}\right]
\end{aligned}
$$

while the expected repayment rate, which is restricted to lie between zero and one, is

$$
E_{t}\left(1-\delta_{t+1}\right)=b_{t}^{-1} \int_{-\infty}^{a_{t+1}^{*}} \pi_{t}\left(a_{t+1}\right) s\left(a_{t+1}, \tau\right) d a_{t+1}+\int_{a_{t+1}^{*}}^{\infty} \pi_{t}\left(a_{t+1}\right) d a_{t+1} \in(0,1) .
$$

Risk premia can be computed as follows (further details on the numerical algorithm that we use to solve the model can be found in appendix 7.2):

1. At the beginning of period $t, b_{t-1}$ is known and the shock to $a_{t}$ realizes. We get solutions $\left\{c_{t}, s_{t}\right\}$ from (19) and (21). Then, we compute the maximum debt repayment capacity using (23) to check whether it is exceeded by $b_{t-1}$ or not.

2. If $\Psi_{t}<b_{t-1}$, the government defaults at the rate $\delta_{t}=1-s_{t} / b_{t-1}$, while end-of-period debt equals zero, $b_{t}=0$. Since default cannot occur in $t+1, E_{t}\left(1-\delta_{t+1}\right)=1$, the bond price equals the risk-free price $1 / R_{t}^{r f}=\beta E_{t}\left(c_{t+1}^{-1} / c_{t}^{-1}\right)$ in this particular period, and $a_{t+1}^{*}=0$.

3 . If $\Psi_{t} \geq b_{t-1}$, the government does not default in period $t$. The bond price $1 / R_{t}$, endof-period debt $b_{t}$, and the productivity threshold $a_{t+1}^{*}$ then simultaneously solve (25), the updated version of (24) which reads $b_{t}=\Psi\left(a_{t+1}^{*}, \sigma_{\varepsilon}, \rho, \tau^{*}\right)$, and the government's flow budget identity

$$
b_{t} / R_{t}=b_{t-1}-s_{t},
$$

which gives the government's demand for funds, while the expected repayment rate 
is determined by $(26)$.

4. After the equilibrium bond price $1 / R_{t}$ is derived, we compute the sovereign risk premium using

$$
R_{t}-R_{t}^{r f}=\frac{c_{t}^{-1}}{\beta E_{t}\left[c_{t+1}^{-1}\left(1-\delta_{t+1}\right)\right]}-\frac{c_{t}^{-1}}{\beta E_{t} c_{t+1}^{-1}}
$$

which is non-zero only if $\Psi_{t} \geq b_{t-1}$.

\section{Results}

In this section we examine how government bonds are priced when investors account for the possibility of sovereign default. The first subsection presents the main novel contribution of the paper: the determination of risk premia in a dynamic general equilibrium model where sovereign default is based on the government's unwillingness to guarantee not to run Ponzi games. We consider uniformly distributed productivity shocks in the first subsection, to gain as much analytical insight as possible. In the second subsection, we consider the case of normally distributed productivity shocks and provide a quantitative assessment of risk premia.

\subsection{A version with uniformly distributed innovations}

To demonstrate how asset prices and public debt are determined in this model, we first apply a simplified version of the model. To lighten the notation in this section, we drop the time index and define $a=a_{t}, a^{\prime}=a_{t+1}, a^{*}=a_{t+1}^{*}$ for all $a \in\left(a_{l}, a_{h}\right)$, where $a_{l}$ and $a_{h}$ are positive constants. We assume that the innovations $\varepsilon$ are uniformly distributed between $a_{l}-\bar{a}$ and $a_{h}-\bar{a}$, and that the productivity level is not serially correlated $(\rho=0)$. Further, to be able to present closed form expressions, we assume that only the first-order terms of the maximum debt capacity (23) are non-negligible.

With these assumptions, consumption, surpluses, and maximum repayable debt are linear functions of the current exogenous state:

$$
\begin{aligned}
& \Psi(a)=\left(1-\tau^{*}\right)\left(\gamma \tau^{*}-\bar{a}^{-1} g\right)(1-\beta)^{-1} a=\theta_{1} a, \\
& c(a)=\gamma(1-\tau) a=\theta_{2} a \\
& s(a)=\tau \gamma(1-\tau) a-(1-\tau) g=\theta_{3} a-\theta_{4},
\end{aligned}
$$

where in each line the second equality sign defines the composite parameters $\theta_{1,2,3,4}>0$. Further, end of period debt satisfies $b=\Psi\left(a^{*}\right)=\theta_{1} a^{*}$ (see 24), and the government budget $(27)$ demands $1 / R=\left(b_{-1}-s\right) / b=\left(b_{-1}-\theta_{3} a+\theta_{4}\right) / \theta_{1} a^{*}$. The asset pricing 
equation $(25)$ can then be written as

$1 / R=\beta a\left\{\left(\theta_{1} a^{*}\right)^{-1}\left[\theta_{3} \int_{-\infty}^{a^{*}} \pi\left(a^{\prime}\right) d a^{\prime}-\theta_{4} \int_{-\infty}^{a^{*}} \pi\left(a^{\prime}\right)\left(1 / a^{\prime}\right) d a^{\prime}\right]+\int_{a^{*}}^{\infty} \pi\left(a^{\prime}\right)\left(1 / a^{\prime}\right) d a^{\prime}\right\}$,

and the expected repayment rate as $E\left(1-\delta^{\prime}\right)=\left(\theta_{1} a^{*}\right)^{-1}\left[\theta_{3} \int_{-\infty}^{a^{*}} \pi\left(a^{\prime}\right) a^{\prime} d a^{\prime}-\theta_{4} \int_{-\infty}^{a^{*}} \pi\left(a^{\prime}\right) d a^{\prime}\right]+$ $\int_{a^{*}}^{\infty} \pi\left(a^{\prime}\right) d a^{\prime}$. Using the assumption of a uniform distribution of $a$ to solve for the integrals, we get the asset pricing equation

$$
1 / R=\beta \frac{a}{a_{h}-a_{l}}\left\{\frac{\theta_{3}\left(a^{*}-a_{l}\right)-\theta_{4}\left(\log a^{*}-\log a_{l}\right)}{\theta_{1} a^{*}}+\left(\log a_{h}-\log a^{*}\right)\right\} .
$$

Defining the RHS of (31) as $G\left(a^{*}\right)=\beta \frac{a}{a_{h}-a_{l}}\left\{\frac{\theta_{3}\left(a^{*}-a_{l}\right)-\theta_{4}\left(\log a^{*}-\log a_{l}\right)}{\theta_{1} a^{*}}+\left(\log a_{h}-\log a^{*}\right)\right\}$ and taking derivatives with respect to $a^{*}$ delivers $G^{\prime}\left(a^{*}\right)=\beta \frac{a}{a_{h}-a_{l}}\left(a^{*}\right)^{-2}\left[\theta_{1}^{-1}\left(\theta_{3} a_{l}-\theta_{4}+\right.\right.$ $\left.\left.\theta_{4} \ln a^{*} / a_{l}\right)-a^{*}\right]$ and $G^{\prime \prime}\left(a^{*}\right)=\frac{a \beta}{\left(a_{h}-a_{l}\right)}\left(a^{*}\right)^{-3}\left[\theta_{1}^{-1}\left(3 \theta_{4}-2 \theta_{4} \ln a^{*}-2 \theta_{3} a_{l}+2 \theta_{4} \ln a_{l}\right)+a^{*}\right]$. The signs of these expressions are difficult to determine in general, but are clear for the relevant case of high values of the discount factor $\beta$. To see this, note that in the limiting case $\beta \rightarrow 1 \Rightarrow \theta_{1}^{-1} \rightarrow 0$ we have $G^{\prime}\left(a^{*}\right)>0$ and $G^{\prime \prime}\left(a^{*}\right)<0$, hence in this case (31) implies the interest rate $R=1 / G\left(a^{*}\right)$ to be an increasing and convex function of the threshold $a^{*}$ and, by $b=\Psi\left(a^{*}\right)=\theta_{1} a^{*}$, of the end of period debt level $b$. The intuitive reason for this positive relation is that future surpluses that suffice to repay debt become less likely for higher thresholds $a^{*}$, which tends to reduce the expected return from bonds (since it increases the probability of default). Thus, investors demand a higher interest rate for compensation.

At the same time, the period budget constraint (27) determines the government's demand for funds. Given the assumptions made in this subsection, it reads

$$
1 / R=\left(b_{-1}-s\right) / b=\left(b_{-1}-\theta_{3} a+\theta_{4}\right) / \theta_{1} a^{*} .
$$

Given the predetermined stock of debt at the beginning of the period $b_{-1}$ and the observed current state $a$, the budget constraint implies that the amount of debt is proportional to the interest rate $R$. Since repayment of a higher end-of-period stock of bonds requires a higher threshold $a^{*}$ (see 24), the budget constraint (32) also leads to a positive relation between the interest rate $R$ and the threshold $a^{*}$ :

$$
R=\Psi\left(a^{*}\right) /\left(b_{-1}-s(a)\right) .
$$

The proportionality between $R$ and $b=\Psi\left(a^{*}\right)=\theta_{1} a^{*}$ reflects the fact that - for a given initial debt level and a given surplus - the government has to issue more debt if the interest rate is higher. 


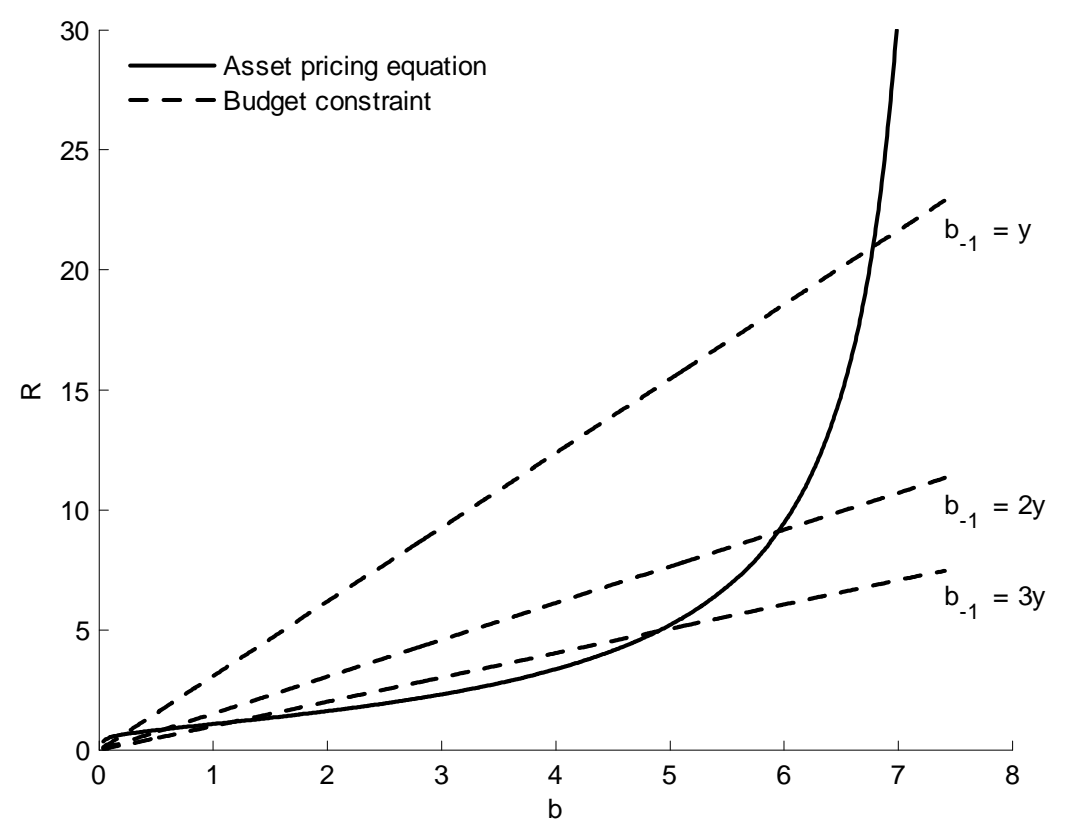

Figure 1: Multiple equilibrium bond prices

For illustration, we use the fiscal policy parameters $\tau=0.38$ and $g / y=0.35$ (see section 4.2 for a more detailed discussion), and standard values for the preference parameters, $\beta=0.99$ and $\gamma$ chosen so that steady state labor supply is $l=1 / 3$ (the corresponding value for $\gamma$ is 0.35 ). We further assume that the uniform distribution is characterized by $a_{h}=1.99, a_{l}=0.01$. We choose initial debt levels to match a debt to gdp ratio (at the mean of the productivity level) equal to 1,2 and 3, respectively. For these parameter values we plot the interest rate $R$ as a function of the end-of-period debt level $b$ (which equals $\theta_{1} a^{*}$ ) in figure 1 , using the pricing equation (31) (the solid line) and the budget constraint $R=\left(b_{-1}-s\right)^{-1} b$ (the dashed lines correspond to the three initial debt levels considered).

In figure 1, the budget equation (33), which gives the government's demand for funds, is sloping upward linearly. At the same time, the asset pricing equation (31), which gives the households' supply of funds, is also upward sloping, but with an increasing slope. ${ }^{9}$ With higher end of period debt levels the interest rate level increases more than proportionally. In the limiting case where default occurs with a probability of almost one, the interest

\footnotetext{
${ }^{9}$ It should be noted that the increasing slope of the RHS of the asset pricing equation (31) does not rely on the non-linear households' stochastic discount factor (and thus on risk aversion). This can be seen from the expected repayment rate, which in case of risk neutral households would equal $1 / \beta$ times the bond price $\left(1 / R=\beta E\left(1-\delta^{\prime}\right)\right): E\left(1-\delta^{\prime}\right)=\left(a_{h}-a_{l}\right)^{-1}\left\{\left[\theta_{3} \frac{1}{2}\left(a^{* 2}-a_{l}^{2}\right)-\theta_{4}\left(a^{*}-a_{l}\right)\right]\left(\theta_{1} a^{*}\right)^{-1}+\left(a_{h}-a^{*}\right)\right\}$.
} 


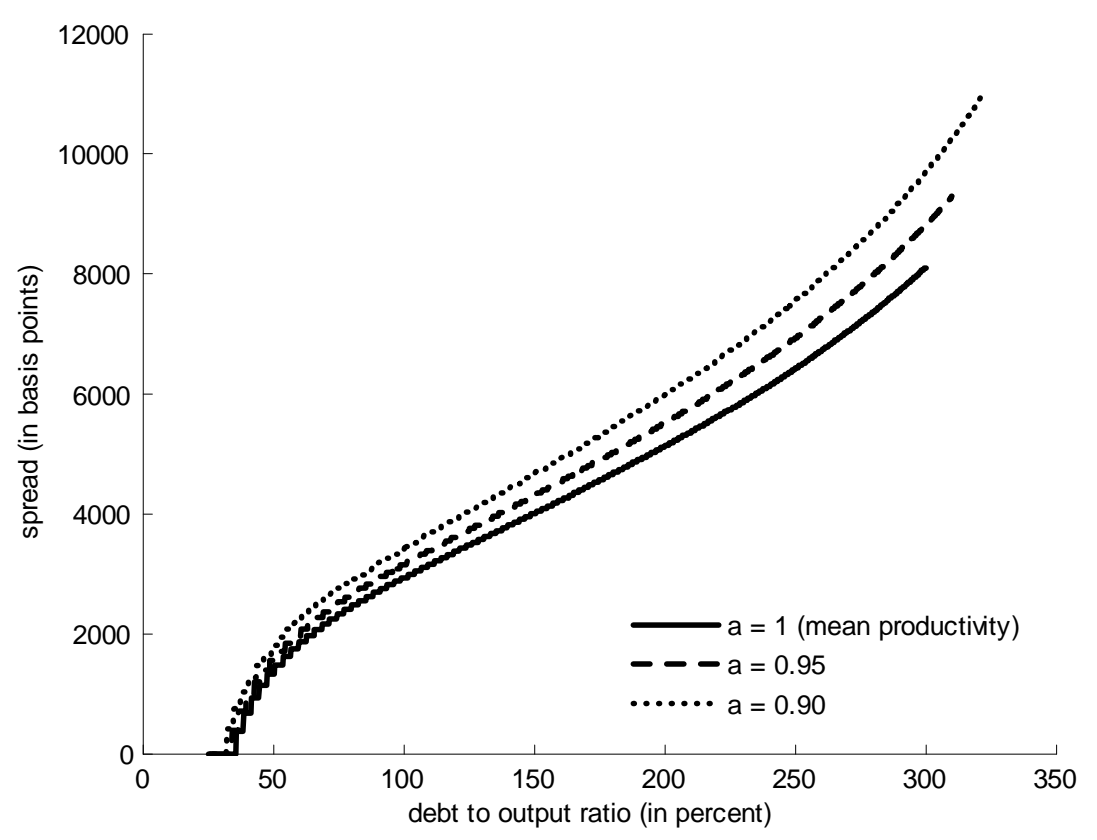

Figure 2: Interest rate spreads for uniformly distributed productivity innovations

rate tends to infinity. Hence, equilibrium credit demand (33) and credit supply (31) imply that there is either no equilibrium or there exist two equilibrium values for the interest rate $R$.

As figure 1 also shows, the lower equilibrium interest rate increases with a higher stock of initially outstanding debt $b_{-1}$. In contrast, the high equilibrium interest rate decreases with higher initial debt. Given this implausible comparative static property of the high equilibrium rate, we will focus on the lower equilibrium interest rate throughout the following analysis. ${ }^{10}$ Thus, assuming that capital market participants coordinate their expectations on low equilibrium interest rates, we examine how the sovereign risk premium behaves in response to a change in the state of the economy. Figure 2 shows the model's implied equilibrium pricing rule, giving the interest rate spread on risky government bonds as a function of the beginning of period ratio of debt to output. The figure shows that the risk premium increases monotonically in the debt to output ratio, and that it is uniformly higher in a situation where the current state of the business cycle is below average (see the dashed and dotted lines in the figure which depict two cases where $a<1$ ).

Thus, in a qualitative sense, the model succeeds in generating risk premia that respond

\footnotetext{
${ }^{10}$ In simulations, we found that the realization of the high equilibrium interest rate would immediately force default.
} 
in an intuitive way to higher levels of indebtedness and to the state of the business cycle, which both determine the risk that the government experiences difficulties to repay. Of course, the risk premia depicted in figure 2 are quantitatively extremely large by empirical standards. This is due to the simplifying assumption made here that the productivity distribution is uniform and there is no persistence of shocks. This implies that all states are equally likely to realize, including those which are fiscally extremely unfavorable.

To conclude, we have shown in this section that risk premia are pervasive - and large even in comparatively good times - if extreme states of the world have a non-negligible probability (as is obviously the case under uniformly distributed shocks). Though stylized, the result shows that under this assumption it is possible, in principle, to theoretically explain interest rate spreads on government bonds through default risk. However, it is clear that the assumption of a uniform distribution is extreme and not likely to be empirically realistic. Therefore, in the next section we will conduct a numerical analysis where the productivity process is more in line with standard assumptions in the business cycle literature.

\subsection{A version with normally distributed innovations}

In this section, we relax the simplifications made above and solve the model numerically for more realistic assumptions about the productivity process. In particular, we assume that the productivity process in (9) can be serially correlated, $\rho>0$, and that innovations $\varepsilon_{t}$ are normally distributed. The parameters are chosen as follows. We interpret one period as a year. The discount rate is therefore set at $\beta=0.97$ to match a standard average value for a risk free annual real interest rate. The tax rate used is $\tau=0.38$ as a representative value for European countries (see references in Trabandt and Uhlig, 2009, who discuss appropriate calibration of average marginal tax rates for European countries in detail). The constant level of government spending $g$ was scaled to lead to a debt level corresponding to $100 \%$ of yearly gdp. As noted in the introduction, this scenario of government debt levels worth one year's output appears to be representative of the situation that many countries will find themselves in quite soon, given the currently observed deficits (see IMF, 2009). We hence choose a government spending level that leads to an average share in output of $g / y=0.35$, in which case the chosen initial debt to output ratio would be constant in an environment without shocks. Thus, we demonstrate that in a stochastic world default risk premia will emerge even if the initial level of debt is sustainable in the sense just described. Further, we set the mean working time share equal to $l=1 / 3$ (and adjust $\gamma$ accordingly).

For the quantitative results, the volatility of the innovations $\varepsilon_{t}$ is of utmost importance. To calibrate it, we regress the log of annual real gdp for the 16 member countries 


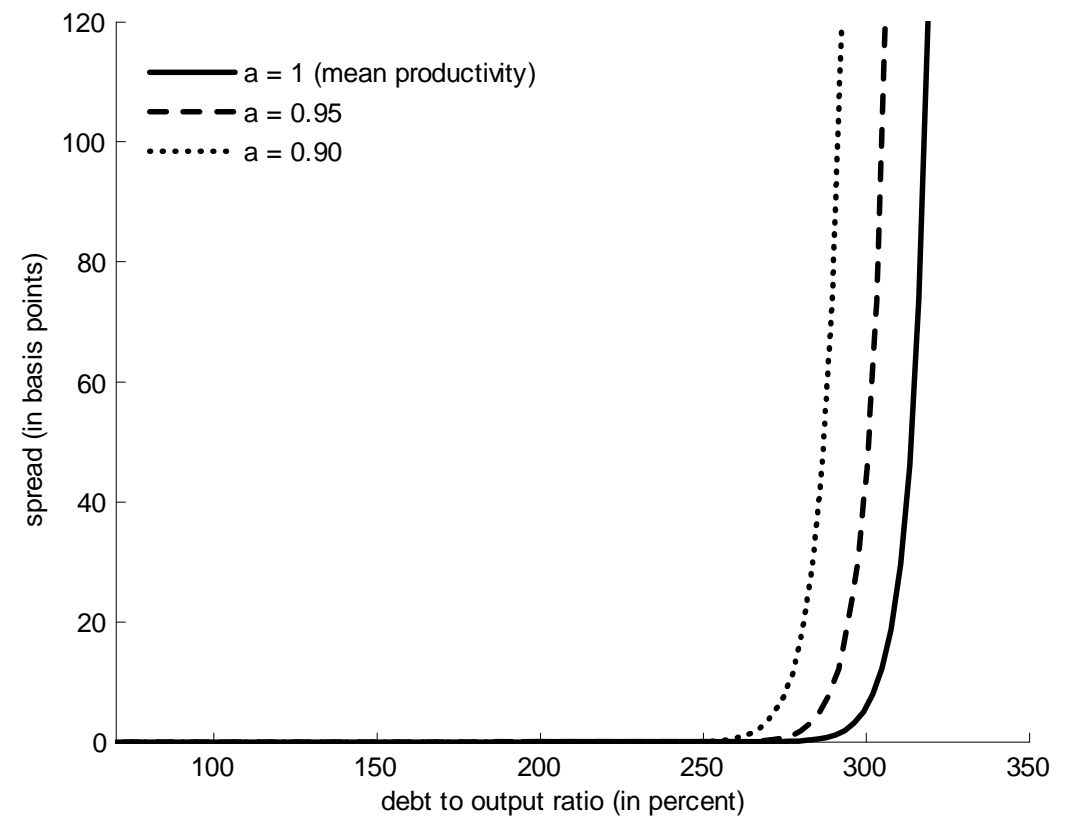

Figure 3: $\rho=0.9$ and st.dev. $\left(\widehat{y}_{t}\right)=0.075$

of the European Monetary Union on a constant and a linear time trend. ${ }^{11}$ The estimated standard deviations of real output range from 3.9 percent for the Netherlands to 15.7 percent for Greece, with a mean of 7.3 per cent. For the benchmark case, we choose the innovation variance in our model such that for a given autocorrelation of $\rho=0.9$, as customarily used in the business cycle literature, the standard deviation of $\widehat{y}_{t}=\log y_{t} / \bar{y}$ from stochastically simulated model runs conforms with this average value. We further consider alternative cases where the autocorrelation coefficient is lowered and the innovation variance is increased. This allows us to see how risk premia would react under more severe macroeconomic fluctuations.

Figure 3 shows the model's pricing rule for risky government bonds for the benchmark parameterization, again as a relation between the default risk spread and the beginning of period ratio of debt to output.The figure shows that with normally distributed and autocorrelated productivity levels, sizeable risk spreads would only occur for extremely high debt ratios exceeding $250 \%$ of gdp. The solid line displays spreads for the steady state productivity level $(a=1)$. Adverse business cycle conditions lead to higher premia

\footnotetext{
${ }^{11}$ Data are from the European Commission's AMECO database; the time span covered is 1960-2008 for 11 out of the 16 countries, but shorter for Malta, Cyprus, Slovakia, Slovenia, and unified Germany, due to data availability.
} 


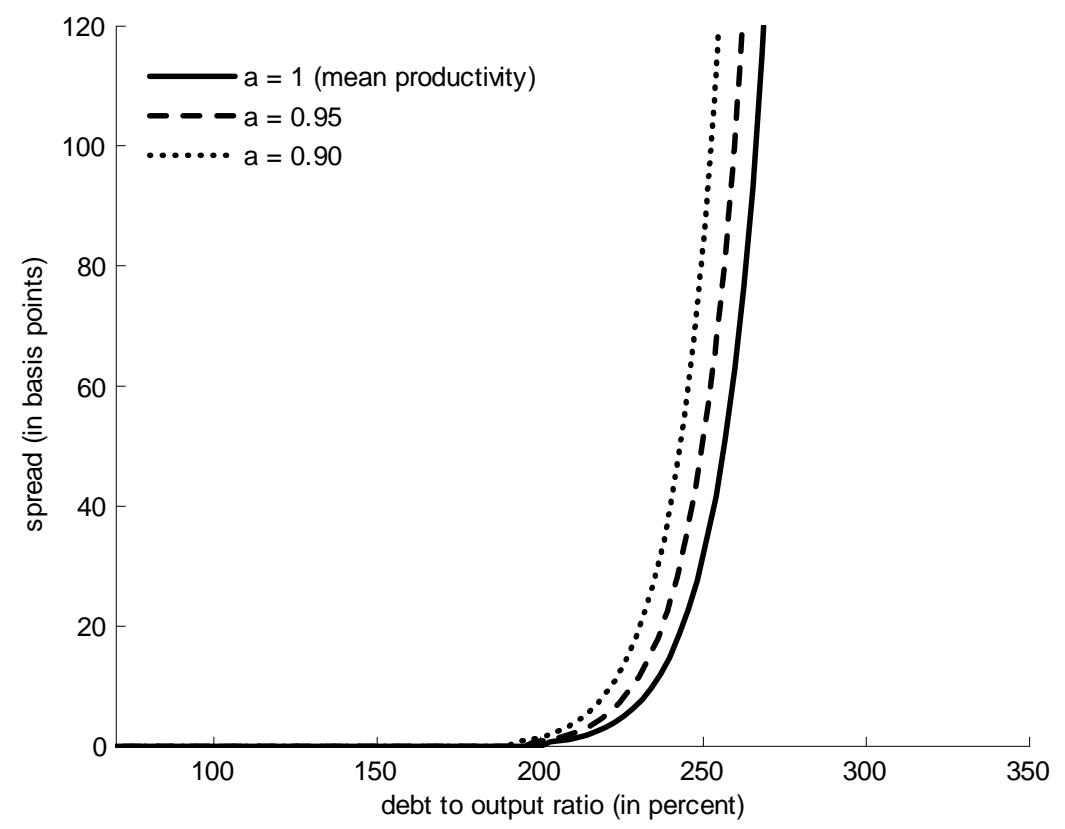

Figure 4: $\rho=0.01$ and st.dev. $\left(\widehat{y}_{t}\right)=0.075$

and occur at somewhat lower debt ratios, as can be seen from the dotted line in the figure which represents a situation where productivity is ten percent below its steady state value. Nonetheless, for the range of debt to gdp ratios that are currently observed, i.e. below or around $100 \%$, the model cannot explain the emergence of risk premia. This is due to the fact that, given the assumptions concerning the government's maximum debt repayment capacity and the size of the underlying variations in the tax base through productivity shocks, default is an unlikely event. This is rationally anticipated by households who are thus willing to lend to the government at or very close to the risk free interest rate, unless the debt to gdp ratio becomes very high.

Consequently, the question arises under which circumstances the model generates default risk premia for debt to output ratios that are empirically observed, like for Belgium and Greece where spreads of 23.7 and 113.9 basis points can be observed for debt to gdp ratios of 88.7 and 96.5 percent, respectively. Figure 4 displays the case of non-persistent shocks $(\rho=0.01)$, where the innovation variance is scaled so that the resulting output variance is the same as before. As a consequence, for each value of $a$ considered in the figures the probability of reaching a fiscally difficult situation through next period's shock realization is higher than before.As figure 4 shows, the pricing rule shifts in leftward direction with non-persistent shocks, as expected, since default has become more likely in 


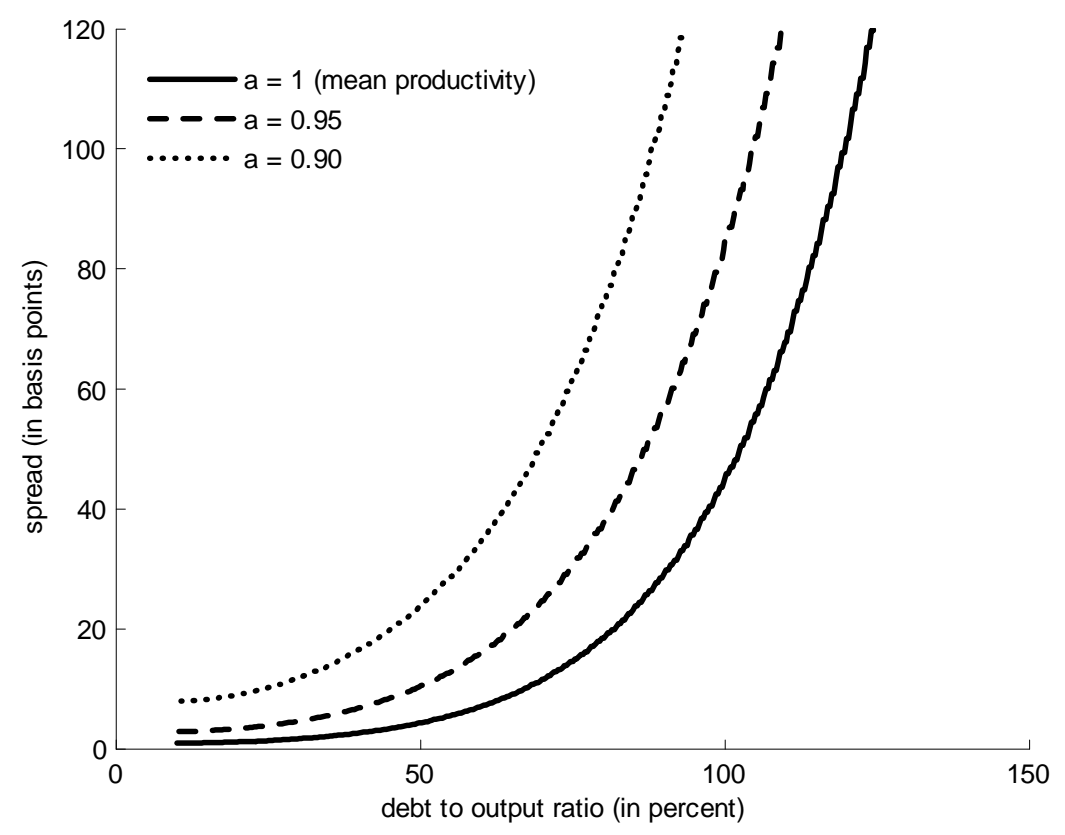

Figure 5: $\rho=0.9$ and st.dev. $\left(\widehat{y}_{t}\right)=4 \cdot 0.075$

intermediate states. However, the implied risk premia still differ from zero only if the government is extremely indebted.

If we calibrate the model to imply a higher variance of output than in our baseline specification, it predicts double-digit basis point risk premia at debt ratios below $100 \%$. This is illustrated in figure 5 , where we set $\rho=0.9$ again and choose the innovation variance in the productivity process so that the implied output variance is four times as high as the average one historically observed for European countries (and thus roughly twice as high as the maximum of the observed output variance for these countries). Under this calibration, the model predicts a relation between spreads and debt to gdp ratios that is comparable to empirical observations mentioned in the introduction.

As revealed by figure 5 , interest rate spreads at moderate debt levels can be rationalized within the model if the variance of productivity shocks is very high (analogously to the case of uniformly distributed shocks in section 4.1 where the implied output variance was also much higher than in the benchmark scenario). The variance of aggregate shocks thus appears as the quantitatively most important factor in explaining default risk premia. The reason is that only in the case of extremely adverse shocks the probability of the government exceeding its repayment capacity is large enough to warrant sizable risk premia. 

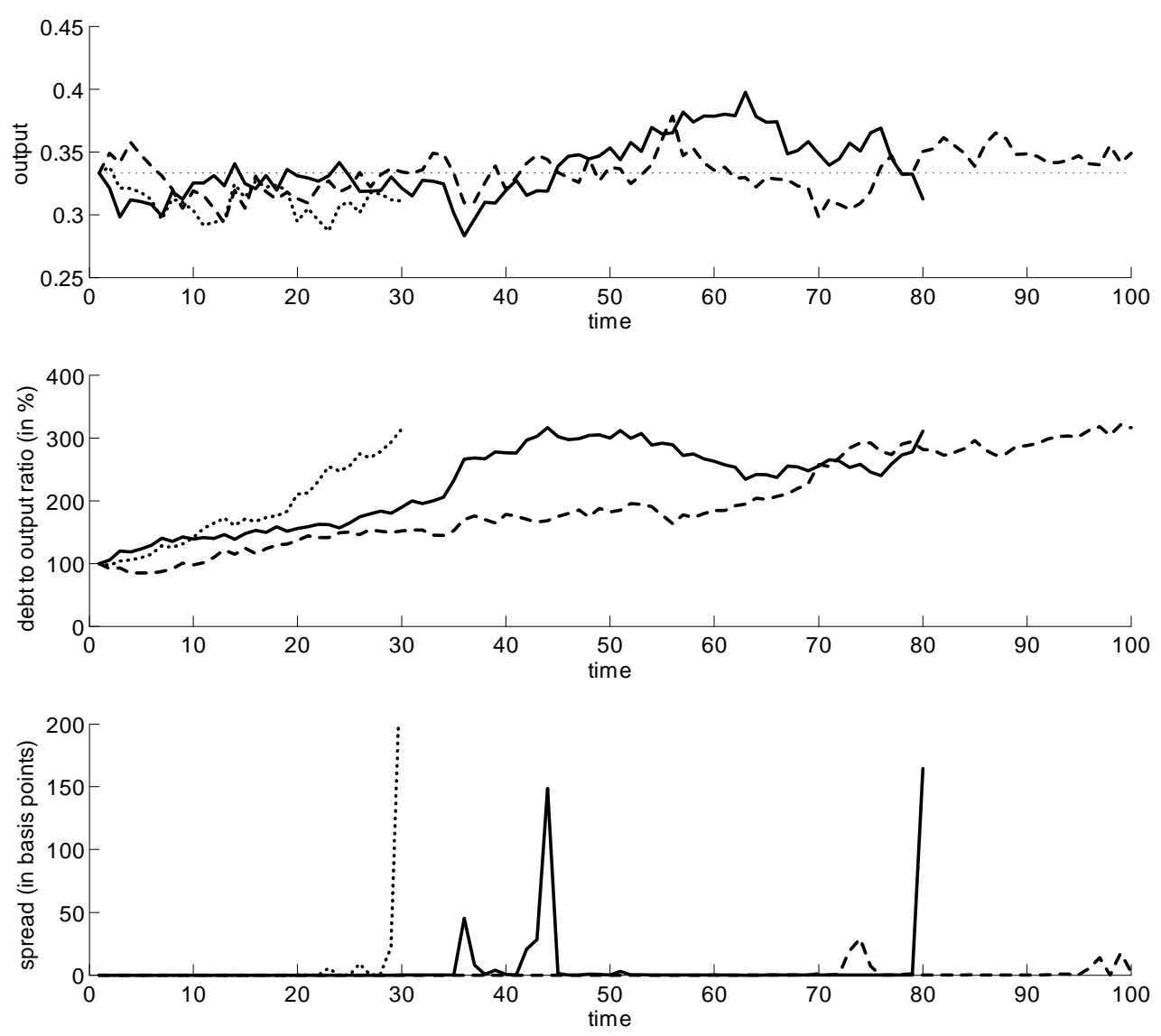

Figure 6: Examples of stochastic simulation runs

Finally, to give a sense of the time series behavior of the simulated model's variables, we stochastically simulated the technology process with $\rho=0.9$ and the volatility of the productivity level set to the baseline case underlying figure 3. Each simulated series exhibits a length of 100 periods. In each of these computational experiments, we recorded output, risk premia, and the debt to output ratio. The simulation runs were stopped when default occurred.

Figure 6 shows three example cases of simulation runs. The upper panel displays simulated output, the middle panel the ratio of debt to gdp, and the lower panel the realized premium in basis points. The examples displayed in figure 6 are chosen because the message they convey is typical for the numerical outcomes. First, the occurrence of premia is obviously rare with the chosen parameterization. Second, premia need not 
necessarily signal impending default, although large premia most of the time do. Third, the example simulations shown in the figure also show that neither high debt levels, nor bad business cycle shocks in themselves necessarily generate risk premia. Rather, it is the combination of these two events that is decisive for the emergence of risk premia.

\section{Conclusion}

This paper was motivated by the question: can empirically observed spreads between interest rates on government bonds of different sovereign issuers in developed countries be theoretically explained as reflecting differential default risk? To study this question, we have proposed a model where default risk is examined in a macroeconomic model with a non-optimizing government issuing one period real bonds. Since the model is rather stylized, the results of this analysis need to be interpreted with some caution, but are nevertheless suggestive.

First, we have derived default risk premia based upon investors' rational expectations of the government being unable to fully serve its debt obligations. A government can enter situations where it cannot avoid running a Ponzi game even if its surpluses were initially sufficient to fully serve debt obligations. Second, this possibility can give rise to multiple equilibrium interest rates on government bonds that contain default risk premia. Third, under uniformly distributed productivity shocks these premia can be large and can exist over the entire support of states. While this specification is rather extreme, it does point out that non-negligible probabilities of extreme states are a candidate way to explain risk premia, and thus sovereign bond spreads. Fourth, if the productivity level is realistically assumed to be normally distributed and serially correlated, risk premia only occur rarely and at hitherto unobserved levels of government debt, and only in the most cyclically vulnerable economies.

Thus, our results can be interpreted in two ways. One interpretation is that asset pricing within a simple macroeconomic framework with aggregate productivity shocks as the only source of uncertainty is unable to explain sovereign default risk premia. Another interpretation is that this class of models and the assumed stochastic processes understate the likelihood of extreme events. This would amount to stating that historical postwar European data do not reflect the true volatility of the underlying shock process, which is nonetheless present in the expectations of asset market participants (an interpretation that might gain some credibility given the depth of the current downturn). We leave the task of assessing the relative merits of each of these interpretations for future research. 


\section{References}

Aiyagari, S. R., 1994, "Uninsured Idiosyncratic Risk and Aggregate Saving," Quarterly Journal of Economics, 109, 659-684.

Aiyagari, S. R., A. Marcet, T. J. Sargent, and J. Seppälä, 2002, "Optimal Taxation without State-Contingent Debt," Journal of Political Economy 110, 1220-1254.

Akitobi, B., and T. Stratmann, 2008, "Fiscal Policy and Financial Markets," Economic Journal 118, 1971-1985.

Arellano, C., 2008, "Default Risk and Income Fluctuations in Emerging Economies," American Economic Review, 98, 690-712.

Bernoth, K., L. Schuknecht, and J. von Hagen, 2004, "Sovereign Risk Premia in the European Bond Market," CEPR Discussion Papers 4465.

Bohn, H., 1998, "The Behavior Of U.S. Public Debt And Deficits," Quarterly Journal of Economics, 113, 949-963-

Codogno, L., C. Favero, and A. Missale, 2003, "EMU and Government Bond Spreads," Economic Policy, 18, 503-532.

Eaton, J. and M. Gersovitz, 1981, "Debt with Potential Repudiation: Theoretical and Empirical Analysis," Review of Economic Studies, XLVII, 289-309.

International Monetary Fund, 2009, The State of Public Finances: Outlook and MediumTerm Policies After the 2008 Crisis, Manuscript, IMF Fiscal Affairs Department.

Ljungqvist, L. and T. J. Sargent, 2004, Recursive Macroeconomic Theory, Cambridge, MIT Press.

Manganelli, S. and G. Wolswijk, 2009, "What Drives Spreads in the Euro Area Government Bond Market?," Economic Policy, 58, 191-240.

Niepelt, D., 2004, "The Fiscal Myth of the Price Level," Quarterly Journal of Economics, 119, 276-299.

Reinhart, C., and K. Rogoff, 2008, "The Forgotten History of Domestic Debt", manuscript, Harvard University.

Schabert, A., 2009, "Monetary Policy Under a Fiscal Theory of Sovereign Default," forthcoming Journal of Economic Theory.

Sims, C., 1994, "A Simple Model for the Study of the Determination of the Price Level and the Interaction of Monetary and Fiscal Policy," Economic Theory, 4, 381-399.

Tauchen, G., 1986, "Finite State Markov-Chain Approximation to Univariate and Vector Autoregressions," Economics Letters, 20, 177-181.

Trabandt, M. and H. Uhlig, 2009, "How Far Are We From The Slippery Slope? The Laffer Curve Revisited," NBER Working Papers 15343.

Uribe, M., 2006, "A Fiscal Theory of Sovereign Risk," Journal of Monetary Economics, 
$53,1857-1875$.

Woodford, M., 1994, "Monetary Policy and Price Level Determinacy in a Cash-in-Advance Economy," Economic Theory, 4, 345-380. 


\section{Appendix}

\subsection{Local approximation of the maximum debt capacity}

In this appendix, we apply a second order approximation of the maximum debt capacity (14). For this, we transform $\Psi_{t}$ in the following way. The surpluses in (14) refer to the nodefault case $\delta_{t+k}=0 \forall k \geq t$, where the Euler equation reads $1 / R_{t+k}^{r f}=\beta E_{t}\left(c_{t+k+1}^{-1} / c_{t+k}^{-1}\right)$. Further, using the law of iterated expectations $\Pi_{i=1}^{k}\left(1 / R_{t+i-1}^{r f}\right)=\left(1 / R_{t}^{r f}\right)\left(1 / R_{t+1}^{r f}\right) \ldots=$ $\beta E_{t}\left(c_{t+1}^{-1} / c_{t}^{-1}\right) \beta E_{t+1}\left(c_{t+2}^{-1} / c_{t+1}^{-1}\right) \ldots=\beta^{k} E_{t}\left(c_{t+k}^{-1} / c_{t}^{-1}\right)$, we can write

$$
\Psi_{t}=E_{t} \sum_{k=0}^{\infty} \beta^{k} \frac{c_{t+k}^{*-1}}{c_{t}^{*-1}} s_{t+k}^{*},
$$

where $c_{t}^{*}=c\left(a_{t}, \tau^{*}\right)$ denotes consumption as a function of the state and the revenue maximizing tax rate $\tau^{*}$. Using the solutions for consumption and government surpluses (19) and (21), we have

$$
\Psi_{t}=c\left(a_{t}, \tau^{*}\right) E_{t} \sum_{k=0}^{\infty} \beta^{k} c\left(a_{t+k}, \tau^{*}\right)^{-1} s\left(a_{t+k}, \tau^{*}\right),
$$

and summarizing terms we get

$$
\begin{gathered}
\Psi_{t}=\Psi\left(a_{t}, \sigma_{\varepsilon}, \rho, \tau^{*}\right)=\gamma\left(1-\tau^{*}\right) a_{t} E_{t} \sum_{k=0}^{\infty} \beta^{k} f\left(a_{t+k}\right), \\
\text { where } f\left(a_{t+k}\right)=\tau^{*}-a_{t+k}^{-1} \gamma^{-1} g .
\end{gathered}
$$

Using that the exogenous state variable $a_{t}$ is generated by a stationary process, we apply a second order Taylor expansion of $E_{t} f\left(a_{t+k}\right)$ at $\bar{a}$, which yields

$$
E_{t} f\left(a_{t+k}\right) \simeq f(\bar{a})+f^{\prime}(\bar{a}) E_{t}\left(a_{t+k}-\bar{a}\right)+\frac{1}{2} f^{\prime \prime}(\bar{a}) E_{t}\left(a_{t+k}-\bar{a}\right)^{2},
$$

where $E_{t} f\left(a_{t+k}\right)=E_{t}\left(\tau^{*}-a_{t+k}^{-1} \gamma^{-1} g\right)$ and

$$
f(\bar{a})=\tau^{*}-\bar{a}^{-1} \gamma^{-1} g, \quad f^{\prime}(\bar{a})=\bar{a}^{-2} \gamma^{-1} g, \quad f^{\prime \prime}(\bar{a})=-2 \bar{a}^{-3} \gamma^{-1} g .
$$

Next, we use that $a_{t+k}$ can be written as

$$
\begin{aligned}
a_{t+k} & =\rho a_{t+k-1}+(1-\rho) \bar{a}+\varepsilon_{t+k}=\rho^{k} a_{t}+\sum_{i=0}^{k-1} \rho^{i}(1-\rho) \bar{a}+\sum_{i=0}^{k-1} \rho^{i} \varepsilon_{t+k-i} \\
& =\rho^{k} a_{t}+\bar{a}\left(1-\rho^{k}\right)+\sum_{i=0}^{k-1} \rho^{i} \varepsilon_{t+k-i}
\end{aligned}
$$


Hence, the mean and the variance of $a_{t+k}$ conditional on information in period $t, E_{t} a_{t+k}$ and $\operatorname{var}_{t} a_{t+k}=E_{t}\left[\left(a_{t+k}\right)^{2}\right]-\left[E_{t} a_{t+k}\right]^{2}$ are given by

$$
\begin{aligned}
E_{t} a_{t+k} & =\rho^{k} a_{t}+\bar{a}\left(1-\rho^{k}\right) \\
\operatorname{var}_{t} a_{t+k} & =E_{t} a_{t+k}^{2}-\left[\rho^{k} a_{t}+\bar{a}\left(1-\rho^{k}\right)\right]^{2} .
\end{aligned}
$$

The term in (38) can, by substituting out $a_{t+k}$ with (36), be simplified to

$$
\begin{aligned}
\operatorname{var}_{t} a_{t+k} & =E_{t}\left[\left(\rho^{k} a_{t}+\bar{a}\left(1-\rho^{k}\right)+\sum_{i=0}^{k-1} \rho^{i} \varepsilon_{t+k-i}\right)^{2}\right]-\left[\rho^{k} a_{t}+\bar{a}\left(1-\rho^{k}\right)\right]^{2} \\
& =\left[\rho^{k} a_{t}+\bar{a}\left(1-\rho^{k}\right)\right]^{2}+E_{t}\left(\sum_{i=0}^{k-1} \rho^{i} \varepsilon_{t+k-i}\right)^{2}-\left[\rho^{k} a_{t}+\bar{a}\left(1-\rho^{k}\right)\right]^{2} \\
& =E_{t}\left(\sum_{i=0}^{k-1} \rho^{i} \varepsilon_{t+k-i}\right)^{2}=\frac{1-\rho^{2 k}}{1-\rho^{2}} \sigma_{\varepsilon}^{2}
\end{aligned}
$$

Using (37), we rewrite (35) as

$E_{t} f\left(a_{t+k}\right) \simeq f(\bar{a})+f^{\prime}(\bar{a}) E_{t}\left(\rho^{k} a_{t}+\bar{a}\left(1-\rho^{k}\right)-\bar{a}\right)+\frac{1}{2} f^{\prime \prime}(\bar{a})\left(E_{t} a_{t+k}^{2}-2 \bar{a} E_{t} a_{t+k}+\bar{a}^{2}\right)$.

Further, using $E_{t} a_{t+k}^{2}=\operatorname{var}_{t} a_{t+k}+\left[\rho^{k} a_{t}+\bar{a}\left(1-\rho^{k}\right)\right]^{2}=\frac{1-\rho^{2 k}}{1-\rho^{2}} \sigma_{\varepsilon}^{2}+\left[\rho^{k} a_{t}+\bar{a}\left(1-\rho^{k}\right)\right]^{2}$, we can simplify $E_{t} f\left(a_{t+k}\right)$ to

$$
\begin{aligned}
E_{t} f\left(a_{t+k}\right) \simeq & f(\bar{a})+f^{\prime}(\bar{a}) E_{t}\left(\rho^{k} a_{t}+\bar{a}\left(1-\rho^{k}\right)-\bar{a}\right) \\
& +\frac{1}{2} f^{\prime \prime}(\bar{a})\left(\frac{1-\rho^{2 k}}{1-\rho^{2}} \sigma_{\varepsilon}^{2}+\left[\rho^{k} a_{t}+\bar{a}\left(1-\rho^{k}\right)\right]^{2}-2 \bar{a}\left[\rho^{k} a_{t}+\bar{a}\left(1-\rho^{k}\right)\right]+\bar{a}^{2}\right) \\
= & f(\bar{a})+f^{\prime}(\bar{a}) \rho^{k}\left(a_{t}-\bar{a}\right)+\frac{1}{2} f^{\prime \prime}(\bar{a})\left[\frac{1-\rho^{2 k}}{1-\rho^{2}} \sigma_{\varepsilon}^{2}+\rho^{2 k}\left(a_{t}-\bar{a}\right)^{2}\right] .
\end{aligned}
$$

Summing up the discounted values of $E_{t} f\left(a_{t+k}\right)$ for $k=0$ to $\infty$, and using (39), we get

$$
\begin{aligned}
\sum_{k=0}^{\infty} \beta^{k} E_{t} f\left(a_{t+k}\right) \simeq & \sum_{k=0}^{\infty} \beta^{k} f(\bar{a})+\sum_{k=0}^{\infty} \beta^{k} f^{\prime}(\bar{a}) \rho^{k}\left(a_{t}-\bar{a}\right) \\
& +\sum_{k=0}^{\infty} \beta^{k} \frac{1}{2} f^{\prime \prime}(\bar{a}) \frac{1-\rho^{2 k}}{1-\rho^{2}} \sigma_{\varepsilon}^{2}+\sum_{k=0}^{\infty} \beta^{k} \frac{1}{2} f^{\prime \prime}(\bar{a}) \rho^{2 k}\left(a_{t}-\bar{a}\right)^{2} \\
= & \frac{1}{1-\beta} f(\bar{a})+f^{\prime}(\bar{a})\left(a_{t}-\bar{a}\right) \sum_{k=0}^{\infty} \beta^{k} \rho^{k} \\
& +\frac{\frac{1}{2} f^{\prime \prime}(\bar{a}) \sigma_{\varepsilon}^{2}}{1-\rho^{2}}\left(\sum_{k=0}^{\infty} \beta^{k}-\sum_{k=0}^{\infty} \beta^{k} \rho^{2 k}\right)+\frac{1}{2} f^{\prime \prime}(\bar{a})\left(a_{t}-\bar{a}\right)^{2} \sum_{k=0}^{\infty} \beta^{k} \rho^{2 k}
\end{aligned}
$$


Since $\beta$ and $\rho$ lie inside the unit circle, the infinite sums converge to finite values:

$$
\begin{aligned}
\sum_{k=0}^{\infty} \beta^{k} E_{t} f\left(a_{t+k}\right) \simeq & \frac{1}{1-\beta} f(\bar{a})+\frac{f^{\prime}(\bar{a})}{1-\beta \rho}\left(a_{t}-\bar{a}\right) \\
& +\frac{\frac{1}{2} f^{\prime \prime}(\bar{a})}{1-\rho^{2}}\left(\sigma_{\varepsilon}^{2}\left(\frac{1}{1-\beta}-\frac{1}{1-\beta \rho^{2}}\right)+\frac{1-\rho^{2}}{1-\beta \rho^{2}}\left(a_{t}-\bar{a}\right)^{2}\right) .
\end{aligned}
$$

Hence, the maximum debt capacity $\Psi$ can be approximated as

$$
\begin{aligned}
& \Psi\left(a_{t}, \sigma_{\varepsilon}, \rho, g, \tau^{*}\right) \\
\simeq & \gamma\left(1-\tau^{*}\right) a_{t} \cdot\left\{\frac{1}{1-\beta} f(\bar{a})+\frac{f^{\prime}(\bar{a})}{1-\beta \rho}\left(a_{t}-\bar{a}\right)\right. \\
& \left.+\frac{\frac{1}{2} f^{\prime \prime}(\bar{a})}{1-\rho^{2}}\left(\sigma_{\varepsilon}^{2}\left(\frac{1}{1-\beta}-\frac{1}{1-\beta \rho^{2}}\right)+\frac{1-\rho^{2}}{1-\beta \rho^{2}}\left(a_{t}-\bar{a}\right)^{2}\right)\right\} .
\end{aligned}
$$




\subsection{Computation}

We replace the original problem presented in sections 2 and 3 by a discrete valued problem, i.e. we assume that the model's state space consists of a finite number of discrete points. First, we describe the setup of the computation. Thereafter, we explain how we simulate the model numerically. The numerical procedure is further used for the pricing rules in section 4.1 and section 4.2 .

\section{A. Setup of the computation}

A1. Choose the following parameters of the model:

\begin{tabular}{lll} 
Parameter & Description & Benchmark Calibration \\
\hline \hline
\end{tabular}

Preferences

$\begin{array}{lll}\bar{l} & \text { Labor in steady state } & 1 / 3 \\ \beta & \text { Discount factor } & 0.99 \\ \gamma & \text { Preference parameter } & \left(\left(1-\frac{g}{y}\right) \bar{l}\right) /(1-\tau)\end{array}$

Productivity process

and state space

$\begin{array}{lll}\rho & \text { Autocorrelation } & 0.9 \\ \sigma_{\varepsilon} & \text { Std. of productivity shocks } & 0.0503 \\ \bar{a} & \text { Unconditional mean of TFP } & 1 \\ n & \text { Number of TFP states } & 1001\end{array}$

Government

$\begin{array}{lll}g / y & \text { Government share } & 0.35 \\ \tau & \text { Tax rate } & 0.38 \\ \tau^{*} & \text { Laffer curve maximizer } & 0.67\end{array}$

A2. Use Tauchen's (1982) algorithm to approximate the continuous valued AR(1)-process for productivity (see 7) by a discrete valued Markov chain. Provide the size of the interval $I_{a}=\left[a_{1}, a_{n}\right]$ and the number of grid points, $n$. Tauchen's algorithm then delivers the exogenous state space of the mode ${ }^{12}$

$$
S=\left\{a_{1}, a_{2}, \ldots, a_{n}\right\}, a_{i}<a_{i+1}, i=1,2, \ldots, n-1,
$$

\footnotetext{
${ }^{12}$ We use equally spaced points $\Delta=a_{i+1}-a_{i}$ for all $i=1,2, \ldots, n-1$.
} 
and the associated transition probability matrix $P=\left(p_{i j}\right)$, whose row $i$ and column $j$ element is the probability of moving from state $a_{i}$ state to state $a_{j}$. Given $\rho$, the interval $I_{a}$ is chosen to include \pm 4 standard deviations of the productivity process. ${ }^{13}$

A3. Given the grid points $S$, use (19), (20), and (21) to compute the policy functions for consumption, labor, and government surpluses, respectively.

A4. Use (23) to compute the maximum debt repayment capacity $\Psi$ for all grid points in the set $S$. Thus, for $\Psi$ we get a vector of $n$ elements where each element gives $\Psi$ if the state of the system is $a_{j} \in S$.

The numerical algorithm to calculate sovereign risk premia is divided into two parts. The calculations performed in the first part do neither depend on government default nor on debt levels. In the second part of the algorithm we proceed recursively to determine $\delta_{t}, b_{t}, a_{t+1}^{*}$, and $R_{t}$.

\section{B. Computing the debt-independent part of the economy}

B1. Use a random number generator and the transition probability matrix $P$ to simulate a time series $t=1, \ldots, T$ of the stochastic state $a$ of length $T$. Assume that the economy is initially in steady state, i.e. $a_{t=1}=\bar{a}$.

B2. Given the simulated sequence for productivity, use the policy functions for $c, l, s$, and $y,(19)-(21)$ and $y_{t}=a_{t} l\left(a_{t}, \tau\right)$, to determine a time series for consumption, labor, surpluses, and output.

B3. Calculate the risk free rate, which is given by

$$
R_{t}^{r f}=\frac{c_{t}^{-1}}{\beta E_{t} c_{t+1}^{-1}} .
$$

In this expression, the conditional expectation $E_{t} c_{t+1}^{-1}$ is calculated as

$$
E_{t} c_{t+1}^{-1}=\sum_{j=1}^{n} p_{i j} \cdot c\left(a_{j}, \gamma, \tau\right)^{-1}
$$

where $i$ denotes the index number for today's stochastic state, $a_{t}$.

\footnotetext{
${ }^{13}$ When computing the pricing rule for the specification that implies st.dev. $\left(\hat{y}_{t}\right)=4 \cdot 0.075$ (see Figure 5 ), the width of the productivity grid is reduced to include \pm 2 standard deviations to ensure $a_{1}>0$.
} 


\section{Computing the debt-dependent part of the economy}

C1. At the beginning of each period the initial debt level, $b_{-1}$, is given. With a randomly drawn realization for the exogenous state $a_{t}$, surpluses $s_{t}=s\left(a_{t}, \gamma, \tau\right)$ and the maximum debt repayment capacity of the current period, $\Psi_{t}=\Psi\left(a_{t}, \sigma_{\varepsilon}^{2}, \rho, \gamma, \tau^{*}\right)$ are also known (see A).

C2. Check whether the government defaults in period $t$ or not.

(a) If $\Psi_{t}<b_{t-1}$, the government defaults and the default rate is calculated as

$$
\delta_{t}=1-s_{t} / b_{t-1}
$$

The end of period debt level equals zero as well as the default rate in $t+1$

$$
b_{t}=\delta_{t+1}=0
$$

Since the government will not default in $t+1$, the asset price therefore equals the inverse of the risk-free rate

$$
\frac{1}{R_{t}}=\frac{1}{R_{t}^{r f}}
$$

To proceed with the next period, go back to step $\mathrm{C} 2$ and set the initial debt level in period $t+1$ to 0 .

(b) If $\Psi_{t} \geq b_{t-1}$, the government does not default on its outstanding debt, $\delta_{t}=0$. Replacing the integrals in (25) by sums over the finite number of states, the asset pricing equation reads

$$
\frac{b_{t-1}-s_{t}}{b_{t}}=\frac{\beta}{c_{t}^{-1}}\left[\begin{array}{c}
b_{t}^{-1} \sum_{a_{t+1}=a_{1}}^{a_{t+1}^{*}} \pi_{t}\left(a_{t+1}\right)\left[c\left(a_{t+1}\right)^{-1} s\left(a_{t+1}\right)\right] \\
+\sum_{a_{t+1}=a_{t+1}^{*}}^{a_{n}} \pi_{t}\left(a_{t+1}\right)\left[c\left(a_{t+1}\right)^{-1}\right]
\end{array}\right]
$$

Use the updated version of $(25)$ to replace $b_{t}=\Psi\left(a_{t+1}^{*}, \sigma_{\varepsilon}, \rho, \gamma, \tau^{*}\right)$ in (40):

$$
\begin{aligned}
& b_{t-1}-s_{t}=\frac{\Psi\left(a_{t+1}^{*}, \sigma_{\varepsilon}, \rho, \gamma, \tau^{*}\right) \beta}{c_{t}^{-1}} \\
& \cdot\left[\begin{array}{c}
\Psi\left(a_{t+1}^{*}, \sigma_{\varepsilon}, \rho, \gamma, \tau^{*}\right)^{-1} \sum_{a_{t+1}=a_{1}}^{a_{t+1}^{*}} \pi_{t}\left(a_{t+1}\right)\left[c\left(a_{t+1}\right)^{-1} s\left(a_{t+1}\right)\right] \\
+\sum_{a_{t+1}=a_{t+1}^{*}}^{a_{n}} \pi_{t}\left(a_{t+1}\right)\left[c\left(a_{t+1}\right)^{-1}\right]
\end{array}\right] .
\end{aligned}
$$

This equation is solved for the unknown productivity threshold in the next period, $a_{t+1}^{*}$, which is its only unknown. To find $a_{t+1}^{*}$, we calculate the right hand side of (41) for all grid points $S$ (corresponding to all possible candidate solutions for $\left.a_{t+1}^{*}\right)$. There are three possible cases: 
i. If the initial debt level net of current surpluses is too high for any possible productivity level $a_{t+1}^{*}$ or if the expected repayment rate $E_{t}\left(1-\delta_{t+1}\right)$ is smaller than zero, there is no solution to (41) and default is inevitable. The default rate equals $\delta_{t}=1-s_{t} / b_{t-1}$, while $1 / R_{t}=1 / R_{t}^{r f}$ and $b_{t}=0$.

ii. If the initial debt level net of current surpluses is too low for any possible productivity level $a_{t+1}^{*}$ or if the expected repayment rate $E_{t}\left(1-\delta_{t+1}\right)$ exceeds one, default will not be expected to occur for any productivity level considered. The bond price is then set equal to the inverse of the risk free rate $1 / R_{t}^{r f}$ and next period's debt level is calculated from the government's budget identity, $b_{t}=\left(b_{t-1}-s_{t}\right) R_{t}^{r f}$.

iii. If there exists a grid point for $a_{t+1}^{*} \in S$, at which the absolute distance between the left hand side and right hand side of (41) is smallest and the slope of the right-hand side of (41) is positive (see the discussion on multiple equilibria in Section 4.1), next-period's debt level $b_{t}$ and the asset price $1 / R_{t}$ are determined by

$$
b_{t}=\Psi\left(a_{t+1}^{*}, \sigma_{\varepsilon}, \rho, \gamma, \tau^{*}\right)
$$

and

$$
\frac{1}{R_{t}}=\frac{\beta}{c_{t}^{-1}}\left[\begin{array}{c}
\Psi\left(a_{t+1}^{*}, \sigma_{\varepsilon}, \rho, \gamma, \tau^{*}\right)^{-1} \sum_{a_{t+1}=a_{1}}^{a_{t+1}^{*}} \pi_{t}\left(a_{t+1}\right)\left[c\left(a_{t+1}\right)^{-1} s\left(a_{t+1}\right)\right] \\
+\sum_{a_{t+1}=a_{t+1}^{*}}^{a_{n}} \pi_{t}\left(a_{t+1}\right)\left[c\left(a_{t+1}\right)^{-1}\right]
\end{array}\right],
$$

where the latter equation is the right hand side of the asset pricing equation (41) (evaluated at $\left.a_{t+1}^{*}\right)$ divided by $b_{t}=\Psi\left(a_{t+1}^{*}, \sigma_{\varepsilon}, \rho, \gamma, \tau^{*}\right)$.

To proceed with the next period $t+1$, use $b_{t}$ as the initial debt level in the next period and go back to step C2.

C3. The time series of risk premia on government bonds is calculated from $R_{t}-R_{t}^{r f}$.

The pricing rules discussed in Section 4.2 can be computed analogously to the stochastic simulation described here. To obtain the pricing rules, use a given grid for the initial debt level, $b_{-1}$, in step $\mathrm{C} 1$ of the procedure and compute the equilibrium interest rate for all realizations on the productivity grid $S$. 

